УДК $81 .+37.013 .2$

DOI: $10.33184 /$ bulletin-bsu-2021.4.59

РОЛЬ ЯЗЫКОВОГО ОБРАЗОВАНИЯ В СОЦИАЛЬНОЙ СРЕДЕ

\author{
(C) М. А. Елинсон*, В. А. Шарипова, О. С. Исхакова, \\ У. С. Шаммасова
}

Башкирский государственный университет

Россия, Республика Башкортостан, 450076 ул. Карла Маркса, 3/4.

Тел.: +7 (917) 3781111 .

*Email: maria_elinson@mail.ru

\begin{abstract}
В данной статье четко прослеживается тесная связь изучения иностранного языка как вида познавательной деятельности с различными особенностями развития личности. При этом успешные результаты в процессе обучения обусловлены не только методическими и общепедагогическими факторами. На первый план выдвигаются психологические особенности языковой личности (характер, темперамент, стрессоустойчивость, самооценка, наличие способностей, потребностей и мотивачии). Аффективные факторы, определяющие эмочиональный фон человека и его отношение к себе и к участникам коммуникативного общения, напрямую связаны с когнитивной составляющей обучающегося. Они же являются определяющими при достижении результата освоения иностранного языка. Обучающая деятельность преподавателя ориентирована на ученика как на субъекта межкультурного общения, сочетающего в себе индивидуальную картину мира, мотивы, потребности, а также социокультурные и индивидуальные особенности развития. Следуя определенным стратегиям преподавателю необходимо обеспечить успешное продвижение в овладении иностранным языком, создавая комфортную обучающую языковую среду для позитивного сотрудничества.
\end{abstract}

Ключевые слова: концепт, многофункииональность, языковая компетенция, когнитивная функция, эколингвистика, речевое общение, межкультурная компетениия, аффективные факторы, самооченка, психологический комфорт.

В современном обществе в свете интеграции мирового образования на первый план выдвигается проблема, связанная с овладением иностранным языком как необходимым компонентом в процессе подготовки современного специалиста любого профиля. Тема «человек в языке» всегда остается интересной и одной из наиболее актуальных в языкознании, ибо именно в мыслительной деятельности человека исследователи находят то звено, которое соединяет реально существующий мир и язык, отражающий этот мир [12, с. 210].

Человек познает мир, подвергая типы знаний определенной когнитивной обработке в соответствии со сложившейся в языке системой концептов, посредством которых осуществляется связь языка с человеческой мыслью, т.к. именно концепты «выступают основными единицами обработки, хранения и передачи знаний».

Язык представляет собой уникальное и многогранное явление, прежде всего потому, что им владеют только люди с целью выражения своих мыслей и эмоций, обмена информацией, познания окружающего мира, достижения консенсуса и т.д. Главным условием существования языка является человеческое общество. В свою очередь, общество не может существовать без языка. Это говорит о том, что язык представляет собой общественное явление. Многофункциональность языка выражена репрезентацией его различных функций: язык является средством общения (коммуникативная функция), средством обозначения, называния предметов, признаков, качеств, действий, событий и т.д. (но- минативная функция), орудием мышления (мыслеоформляющая функция), средством познания окружающего мира (когнитивная функция), средством восстановления в памяти ранее познанного (репрезентативная функция), средством накопления знаний человека о реальном мире (кумулятивная функция), средством сохранения для потомков накопленного человеческого опыта и средством передачи культурно-исторических ценностей народа от поколения к поколению [5, с. 787]. В процессе речевого общения язык выполняет и ряд других не менее важных функций, а именно - экспрессивную, эстетическую, апеллятивную, эмотическую, контактноустанавливающую, метаязыковую, этическую и др. Каждый народ образует свою собственную картину мира с помощью языка. Она представляет собой языковую интерпретацию действительности, которую можно представить в форме размышлений о мире, закрепленных в грамматических формах, лексике, текстах и т.д. Из этого следует, что язык является инструментом коммуникации, мышления и познания. По мнению 3. Д. Попова и И. А. Стернина, национальная картина мира проявляет себя в единообразии поведения народа в стереотипных ситуациях, в общих представлениях народа о действительности, в высказываниях, суждениях о действительности, пословицах, поговорках и афоризмах [9]. По их мнению, эти общности представлений и поведения народа, отраженные в языковой картине мира, воспринимаются как стереотипы, которые когнитивная лингвистика рассматривает как стандартное мнение о социальных 
группах или как об отдельных представителях этих групп. В 70-е гг. появляется новый термин, определяющий значение языка в языковой картине мира. «Языковая экология», или «экология языка», представляет язык как часть экосистемы, в которой он формируется и эволюционирует, как и любой живой организм, удовлетворяя при этом все потребности своих пользователей [15]. Тесное взаимодействие лингвистических и экологических факторов привело к появлению эколингвистики, благодаря которой появилась возможность по новому описать алгоритм действий языковых механизмов с целью совершенствования полилингвального общения в условиях современного общества.

По словам Н. Д. Гальсковой и Н. И. Гез, обращение к языку как общественному явлению, включенному в общественно-практическую деятельность человека и обслуживающему его социальное «бытование», позволяет выявить модель способностей к речевому общению, которая должна выступать в качестве результата обучения [2, с. 145]. При этом речь идет о развитии языковой личности как носителе не только языка, но и определенной картины мира, а также и о вторичной языковой личности, которая формируется в процессе обучения неродным языкам. Это еще раз подтверждает тот факт, что личность обучаемого является главным условием успешного языкового образования в целом.

Нацеленность на концепт вторичной языковой личности позволяет определить целевые и содержательные аспекты языкового образования в «двухплановом единстве». Аутентичная языковая личность существует и развивается только в условиях конкретного лингвосоциума с определенной картиной мира, отвечающей ее духовным, физическим, эстетическим, технологическим и другим потребностям, в то время как вторичная языковая личность характеризуется процессом овладения иностранным языком через коммуникативно-познавательный потенциал языкового инофона. Из этого следует, что при обучении неродным языкам необходимо развивать не только коммуникативную способность языка, но также и его вторичное языковое и когнитивное сознание. Появляется острая необходимость формировать у учащихся навык использовать иностранный язык в различных жизненных ситуациях, а также научить иному образу мысли и сознания, характеризующим носителя иного «языкового» мира. Это указывает на способность, позволяющую языковой личности реализовать себя в рамках диалога культур, т.е. в рамках межкультурной коммуникации. Данный феномен называют межкультурной компетенцией. По словам О. Д. Митрофановой, ее становление осуществляется во взаимосвязи освоения иноязычного кода и развития культурного опыта человека, в составе которого можно вычленить отношение человека к себе, к миру, а также опыт творческой деятельности [8]. Иначе говоря, межкультурная компе- тенция формируется в процессе развития учащегося, его способности и умения принимать участие в диалоге культур, основываясь на принципах корпорации, взаимного уважения и понимания, принятия культурных особенностей и различий. В этом процессе исходная культура изучающего язык играет важную роль, являясь средством познания не только чужой, но и своей культуры. Межкультурная компетенция в современных лингвистических учениях трактуется по-разному. По мнению А. КнаппПоттхоффа, межкультурная компетенция характеризуется тремя структурными компонентами. Аффективный компонент представлен эмпатией и толерантностью. Когнитивный компонент охватывает знания о родной культуре и культуре страны изучаемого языка, а также общие знания о культуре и коммуникации [17]. Опираясь на эти исследования, Е. В. Малькова отмечает, что межкультурная коммуникация определяет онтологический аспект становления личности, а коммуникативная - ее языковые и речевые способности. При этом становление межкультурной компетенции возможно при развитии коммуникативной. Понятие коммуникативной компетенции в полной мере обогащается данными деятельностных теорий (дискурсивный анализ, теория речевых актов). В соответствии с ними процесс обучения представляет собой не только передачу и прием информации, но и регулирование отношений между партнерами [4, с. 877]. Согласно требованиям образовательных стандартов и учебных программ, коммуникативная компетенция является базовой в рамках изучения дисциплины «Иностранный язык» и раскрывает способность пользоваться иностранным языком для решения задач межличностного и межкультурного взаимодействия. Очевиден и тот факт, что при формировании необходимых знаний, умений и навыков у обучаемых в неязыковом вузе, преподаватели иностранного языка сталкиваются с рядом проблем. По словам И. Ф. Шерстковой и Д. Г. Халиковой, остро встает проблема мотивированности обучаемых, учебные группы с разноуровневыми знаниями, а также ограниченные учебные пособия, не дающие возможность активно усвоить требуемый материал, вывести в речь полученные знания и навыки [13, с. 211]. Следует заметить, что процесс приобретения знаний действительно требует особого эмоционального и психологического состояния обучаемого. Такие разнообразные эмоции, как раздражение, страх, скука, создают дополнительные проблемы в ходе усвоения новой языковой информации. Это может привести к полной или частичной потере интереса к процессу обучения. Как известно, различного рода социально-экономические проблемы в современном обществе приводят к остро назревшим вопросам, касающимся лингвоэкологии, о которой упоминалось ранее. В российских школах и вузах отмечается стойкая тенденция к ухудшению экологии общения. В связи с этим назрела необходимость 
разработки таких образовательных инструментов и технологий, которые способны смягчить последствия неблагоприятных тенденций общественного развития [11]. По словам Е. А. Казанцевой, одной из возможных преград для успешного развития образования является нарушение экологического баланса общения между педагогами и обучающимися в силу недостаточности, по сравнению с европейскими языками, разработанности и воспроизведения норм русского академического языка [7, с. 893]. На самом деле в процессе обучения иностранному языку иногда происходит нарушение общедидактических принципов. Например, вместо сознательного усвоения иноязычного материала, обучающиеся заучивают подготовленные тексты и диалоги, что нарушает принцип сознательности. Принцип активности зачастую приводит к тому, что обучающийся активен только в том случае, если его намеренно спрашивает учитель, и т.д. Во избежание этих последствий, необходимо как можно ближе приблизить процесс овладения иностранным языком к овладению им в естественной языковой среде с его практическим использованием.

В последнее время в современной литературе активно обсуждается проблема, касающаяся влияния различных психолингвистических факторов на методику преподавания в процессе обучения иностранным языкам. В связи с этим аффективные факторы являются определяющими критериями для описания эмоционального состояния человека, а также его отношение к самому себе и участникам коммуникации. Аффективные факторы определяют взаимоотношения между преподавателем и студентом при языковом взаимодействии, что напрямую связано с психологическим состоянием обучающегося. Чем успешнее студент, чем выше его уровень овладения иностранным языком, тем лучше он умеет контролировать свои эмоции и быстро справляться с возникшими на пути трудностями и неудачами. Это еще раз доказывает то, что успешность овладения иностранным языком имеет важную психологическую составляющую. Эта проблема широко освещается в работах известных ученых-лингвистов. И. А Зимняя, активно изучая психологию изучения и овладения иностранным языком, определяет такие важные психологические факторы, как интенсивность общения, включение языка в предметную и коммуникативную деятельность, соотнесение с сензитивными периодами речевого развития человека [6, с. 787]. По словам А. А. Леонтьева, особое внимание необходимо обратить на специфику формирования психофизиологического механизма. Речь идет о языковой способности каждого носителя языка, развивающуюся под влиянием речевого общения [10]. Е. Н. Добрынина, в свою очередь, пришла к выводу о том, что разные психотипы отличаются в достижении успешного результата во владении иностранными языками [3, с. 22]. Не вызывает сомнений и тот факт, что такие особенности психических познавательных процессов обучающегося, как внимание, память, воображение, восприятие, оказывают большое влияние на успех в процессе обучения. Ведь, например, в процессе мышления обучающийся выполняет много разных мыслительных операций, таких как анализ, синтез, обобщение, сравнение и т.д.

В работах различных ученых четко разграничиваются 2 вида способностей к овладению иностранного языка. Говоря о лингвистических или языковых способностях необходимо указать на психологические и индивидуальные различия, которые являются ключевыми и приводят к успешному овладению лексикой, грамматикой, чтением и фонетикой. Коммуникативные и речевые способности, в свою очередь, связаны с особенностями коммуникативных умений и навыков, с чтением, устной речью, письмом и восприятием текста.

Так как процесс овладения иностранным языком представляет собой познавательную деятельность, направленную на развитие личности обучающегося, необходимо учитывать его психологические характеристики, такие как коммуникабельность, экстравертированность, эмпатию, тревожность, эффект социальной фасилитации и ингибиции, самооценку [14]. Согласно проведенным исследованиям, на успешность в процессе овладения иностранным языком, прежде всего, влияют тревожность и самооценка. Высокий уровень тревожности мешает успешному усвоению иностранного языка. Что касается заниженного уровня тревожности, он также приводит к негативному воздействию на человека, т.к. может быть выражен в скованности или, наоборот, раскованности в процессе овладения иностранным языком. Скованность приводит к боязни совершить ошибку, а чрезмерная раскованность также не всегда приводит к желаемому результату. Самооценка четко выражает отношение человека к самому себе. Она указывает на то, до какой степени человек верит в свои силы и возможности и определяет свою значимость. Для успеха в любой деятельности необходим определенный уровень самооценки, знаний о себе и окружающем мире. Самооценка представляет собой самый мощный аффективный фактор как для успеваемости обучающихся в целом, так и для успешного изучения иностранного языка $[1$, с. 55]. В работах Д. Брауна описываются три типа самооценки. Глобальная или общая характеризует личность в целом и касается эмоционального уровня, который почти не поддается коррекции. Ситуативная самооценка проявляет себя при оценивании индивидом определенных обстоятельств, которые способны меняться в зависимости от ситуаций (в образовательном учреждении, на работе, дома). Этот тип самооценки напрямую связан с такими личностными качествами, как общительность, гибкость, стрессоустойчивость и др. Третий связан с выполнением конкретной задачи, в процессе освоения какого-либо навыка $[14$, с. 70$]$. Этот тип напрямую связан со спонтанной речью на иностранном языке, 
характеризуемой как обмен эмоциональными составляющими между участниками коммуникативного общения. В процессе неподготовленного высказывания обучающийся допускает ошибки и зачастую оценивает и сравнивает себя с другими. При этом необходимо, чтобы учащийся четко понимал роль ошибок в процессе обучения. Многие студенты стараются не участвовать в процессе спонтанного говорения, боясь при этом критики окружающих, а также потери авторитета. Молчание, в свою очередь, не дает возможности отработать коммуникативные навыки. Таким образом, преподавателю необходимо научить студента воспринимать ошибки как естественный компонент в процессе обучения, а также исправлять их для дальнейшего продвижения и развития языковой компетенции. Только такой подход позволит не снизить самооценку и мотивацию. Психологический стресс и другие негативные факторы при высокой самооценке способствуют сохранению желания продолжать совершенствоваться для достижения высоких результатов. При низкой самооценке студент чувствует свою некомпетентность из-за негативного отношения к самому себе, испытывает страх, выступая перед аудиторией. В настоящее время перед преподавателями стоит непростая задача для достижения студентами более высоких результатов. Необходимо всеми средствами способствовать повышению самооценки студентов для достижения лучших результатов, выражая свое одобрение, оказывая психологическую поддержку и поощряя к дальнейшему совершенствованию языковой компетенции. Студенты должны быть уверены в том, что чем больше усилий они прилагают, тем больше шансов на успех [16]. Создание психологического комфорта, позитивный настрой и поощрение обучающихся позволят достичь высоких результатов в процессе обучения иностранным языкам. По мнению некоторых исследователей, одним из инструментов повышения эффективности образовательного процесса в вузе может быть создание единого цифрового пространства знаний, которое позволит объединить участников образовательного процесса на едином цифровом поле для свободного обмена знаниями $[18$, с. 160$]$.

Подводя итог всему вышесказанному, мы приходим к выводу, что процесс обучения должен иметь открытый характер, нацеленный на ярко выраженную личностно ориентированную направленность, что еще раз доказывает, что языковая личность является ядром этого процесса. Предметная компетенция и профессиональное мастерство учителя, индивидуальная картина мира и собственные особенности межкультурного общения ученика выступают как равноправные субъекты успешного процесса обучения. При этом эмоциональные характеристики в значительной степени влияют на высокий результат в процессе овладения иностранными языками. Обращая внимание на различные психологические аспекты преподавания, природу индивидуальных различий учащихся, а также способность находить контакт с различными типами личности, учитывая аффективные факторы, преподаватели создают комфортные условия для личностного языкового роста в современном развивающемся обществе.

\section{ЛИТЕРАТУРА}

1. Восковская А. И., Карпова Т. А. Роль самооценки студентов в процессе изучения иностранного языка в неязыковом вузе // Мир педагогики и психологии. 2019. №1(30). Январь.

2. Гальскова Н. Д., Гез Н. И. Теория обучения иностранным языкам: Лингводидактика и методика: учеб. пос. для студ. лингв. ун-тов и фак. ин. яз. высш. пед. учеб. заведений. М.: Академия, 2004. 336 c.

3. Губик С. В., Шаммасова У. С. Приоритетные направления развития научно-образовательного центра в Республике Башкортостан // Экономика и управление: научно-практический журнал. 2020. №2(152). С. 157-161.

4. Добрынина Е. Н. Индивидуально-типологические предпосылки успешности овладения иностранным языком // Вузовская наука: из настоящего в будущее: мат-лы V рег. межвузовской научно-практ. конф. Кисловодск: СевКавГТУ, 2004. С. 20-24.

5. Елинсон М. А., Шарипова В. А, Исхакова О. С. Процесс коммуникации в сфере коммуникативного взаимодействия // Вестник Башкирского университета. 2018. Т. 23. №3. С. 877-881.

6. Закирьянов К. З. Проблема сохранения родных языков // Вестник Башкирского университета. 2018. Т. 23. №3.

7. Зимняя И. А. Психология обучения иностранным языкам в школе. М., 1991.

8. Казанцева Е. А. Категории «уважение» и «вежливость» в английской и русской академических лингвокультурах // Вестник Башкирского университета. 2018. Т. 23. №3. С. 893-898.

9. Митрофанова О. Д. Лингводидактические уроки и прогнозы конца XX века // Мат-лы IX конгресса МАПРЯЛ. Братислава, 1999.

10. Попова 3. Д., Стернин И. А. Язык и национальная картина мира. Изд. 4-е, стер. М.; Берлин: Директ-медиа, 2015.

11. Рубинштейн С. Л. Проблемы способностей и вопросы психологической теории // Вопросы психологии. 1960. No. 3. С. 3-15.

12. Фаткуллина Ф. Г., Сулейманова А. К. Региональная образовательная система на пути интеграции: проблемы и перспективы // Мат-лы Междунар. научно-практ. конф. «Культура и образование в XXI веке», Ч. 2. 2-5 февраля 2014 г. Горно-Алтайск; Барнаул, 2014. С. 138-146.

13. Шарипова В. А, Елинсон М. А, Исхакова О. С. Интернеткоммуникация: новые возможности и способы опосредованного общения или деградация языка // Вестник Башкирского университета. 2019. Т. 24. №1. С. 210-214.

14. Шарипова В. А., Шакирова Н. Р., Елинсон М. А. Объективация в языке функционально-когнитивной сферы «речевая деятельность» (сопоставительное исследование на мат-ле рус. и англ. языков) // Вестник Московского ун-та. Серия 9: Филология. 2017. №2. С. 70.

15. Шерсткова И. А., Халикова Д. Г. Формирование межкультурной иноязычной компетенции у студентов неязыкового вуза в первый год обучения: проблемы и решения // Филологические науки. Вопросы теории и практики. 2017. №11(77). Ч. 2.

16. Brown D. H. Principles of Language Learning and Teaching (5th ed). Pearson: Longman, 2007.

17. Haugen E. I. The Ecology of Language: essays by Einar Haugen. Selected and Introduced by Anwar S. Dill. Standford, California: Standford University Press, 1972.

18. Kirbi E., McDonald J. Engage every student: Motivation tools for teachers and parents. USA: Search Institute Press, 2009.

19. Knapp-Potthoff A. Interkulturelle Kommunikationsfähigkeit als Lernziel // Aspekte inetrkultureller Kommunikationsfähigkeit / Hrsg. A. Knapp-Potthoff, M. Liedke. München, 1997. 
DOI: 10.33184/bulletin-bsu-2021.4.59

\title{
THE ROLE OF LANGUAGE EDUCATION IN SOCIAL SPHERE
}

\section{(C) M. A. Elinson*, V. A. Sharipova, O. S. Iskhakova, U. S. Shammasova}

\author{
Bashkir State University \\ 3/4 Karl Marx Street, 450076 Ufa, Republic of Bashkortostan, Russia.
}

Phone: +7 (917) 3781111 .

*Email: maria_elinson@mail.ru

The authors of the article trace a close connection between learning foreign language as a type of cognitive activity with various characteristics of personal development. At the same time, successful results in the learning process depend on not only methodological and general pedagogical factors. Some psychological characteristics of any linguistic personality (character, temperament, resistance to stress, self-esteem, mental abilities, needs and motivation) are highlighted. Affective factors that determine the emotional background of a person and their attitude to themself and to participants in communication are directly related to the cognitive component of the student. These factors are also determinative in achieving the result of mastering a foreign language. Educational activity of the teacher is focused on the student as a subject of intercultural communication, combining an individual picture of the world, motives, needs, as well as socio-cultural and individual characteristics of the development. Following certain strategies, the teacher needs to ensure successful progress in mastering a foreign language, creating a comfortable learning language environment for positive cooperation. In the course of educational activities, the teacher needs to pay attention to a number of problems of methodological and psychological nature, which will lead to a decrease in the level of emotional stress of students. It satisfies the necessity to apply individualization, speech orientation in the learning process, as well as the accessibility of the subject and the psychological mobility of the teacher.

Keywords: concept, multifunction, language competence, cognitive function, ecolinguistics, speech communication, intercultural competence, affective factors, self-esteem, psychological comfort.

Published in Russian. Do not hesitate to contact us at bulletin_bsu@mail.ru if you need translation of the article.

\section{REFERENCES}

1. Voskovskaya A. I., Karpova T. A. Mir pedagogiki i psikhologii. 2019. .No. 1(30). Yanvar'.

2. Gal'skova N. D., Gez N. I. Teoriya obucheniya inostrannym yazykam: Lingvodidaktika i metodika: ucheb. pos. dlya stud. lingv. un-tov i fak. in. yaz. vyssh. ped. ucheb. zavedenii [Theory of teaching foreign languages: Linguodidactics and methodology: textbook for students of linguistic universities and the departments of foreign languages of pedagogical universities]. Moscow: Akademiya, 2004.

3. Gubik S. V., Shammasova U. S. Ekonomika i upravlenie: nauchno-prakticheskii zhurnal. 2020. No. 2(152). Pp. 157-161.

4. Dobrynina E. N. Vuzovskaya nauka: iz nastoyashchego v budushchee: mat-ly V reg. mezhvuzovskoi nauchno-prakt. konf. Kislovodsk: SevKavGTU, 2004. Pp. 20-24.

5. Elinson M. A., Sharipova V. A, Iskhakova O. S. Vestnik Bashkirskogo universiteta. 2018. Vol. 23. No. 3. Pp. 877-881.

6. Zakir'yanov K. Z. Vestnik Bashkirskogo universiteta. 2018. Vol. 23. No. 3.

7. Zimnyaya I. A. Psikhologiya obucheniya inostrannym yazykam v shkole [Psychology of teaching foreign languages at school]. Moscow, 1991.

8. Kazantseva E. A. Vestnik Bashkirskogo universiteta. 2018. Vol. 23. No. 3. Pp. 893-898.

9. Mitrofanova O. D. Mat-ly IX kongressa MAPRYaL. Bratislava, 1999.

10. Popova Z. D., Sternin I. A. Yazyk i natsional'naya kartina mira [Language and national picture of the world]. Izd. 4-e. M.: Direkt-media, 2015.

11. Rubinshtein S. L. Voprosy psikhologii. 1960. No. 3. Pp. 3-15.

12. Fatkullina F. G., Suleimanova A. K. Mat-ly Mezhdunar. nauchno-prakt. konf. «Kul'tura i obrazovanie v XXI veke», Pt. 2. 2-5 fevralya 2014 g. Gorno-Altaisk; Barnaul, 2014. Pp. 138-146.

13. Sharipova V. A, Elinson M. A, Iskhakova O. S. Vestnik Bashkirskogo universiteta. 2019. Vol. 24. No. 1. Pp. $210-214$.

14. Sharipova V. A., Shakirova N. R., Elinson M. A. Vestnik Moskovskogo un-ta. Seriya 9: Filologiya. 2017. No. 2. Pp. 70.

15. Sherstkova I. A., Khalikova D. G. Filologicheskie nauki. Voprosy teorii i praktiki. 2017. No. 11(77). Pt. 2.

16. Brown D. H. Principles of Language Learning and Teaching (5th ed). Pearson: Longman, 2007.

17. Haugen E. I. The Ecology of Language: essays by Einar Haugen. Selected and Introduced by Anwar S. Dill. Standford, California: Standford University Press, 1972.

18. Kirbi E., McDonald J. Engage every student: Motivation tools for teachers and parents. USA: Search Institute Press, 2009.

19. Knapp-Potthoff A. Aspekte inetrkultureller Kommunikationsfähigkeit. Hrsg. A. Knapp-Potthoff, M. Liedke. München, 1997. 